\title{
Influence of neutral ligands on the structures of silver(I) sulfonates
}

Fang-Fang Li, Jian-Fang Ma,* Shu-Yan Song, Jin Yang, Ying-Ying Liu and Zhong-Min Su

Department of Chemistry, Northeast Normal University, Changchun 130024, People's Republic of China.

\section{Supporting information}

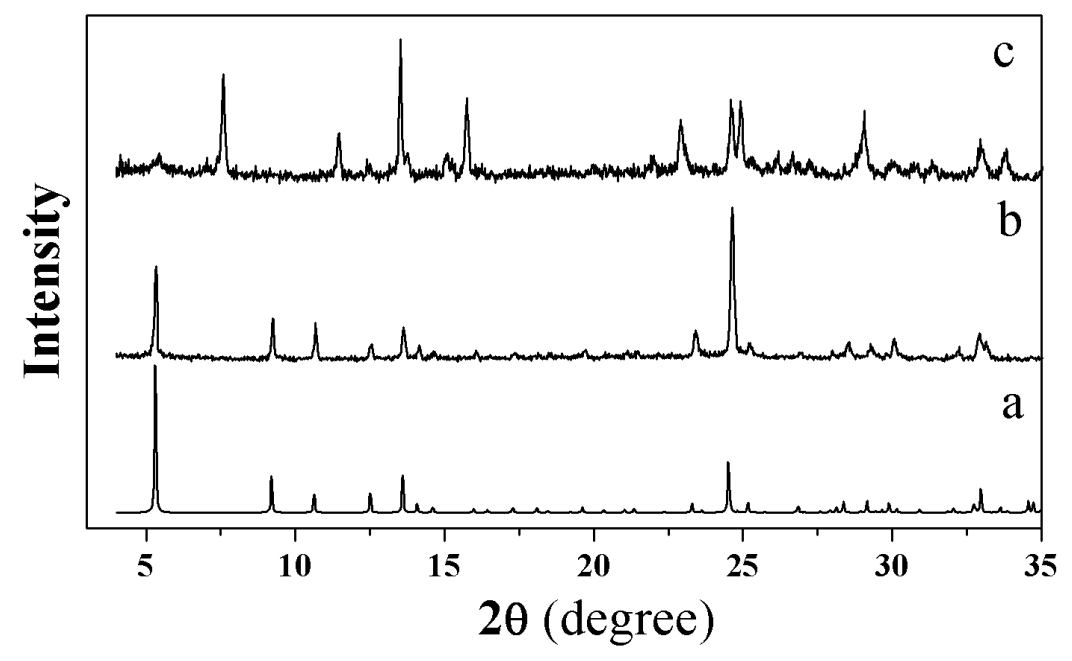

Figure S1. XRPD patterns for 1: (a) the simulated PXRD pattern calculated from the single-crystal structure, (b) taken at room temperature, (c) after heating to $120^{\circ} \mathrm{C}$. 


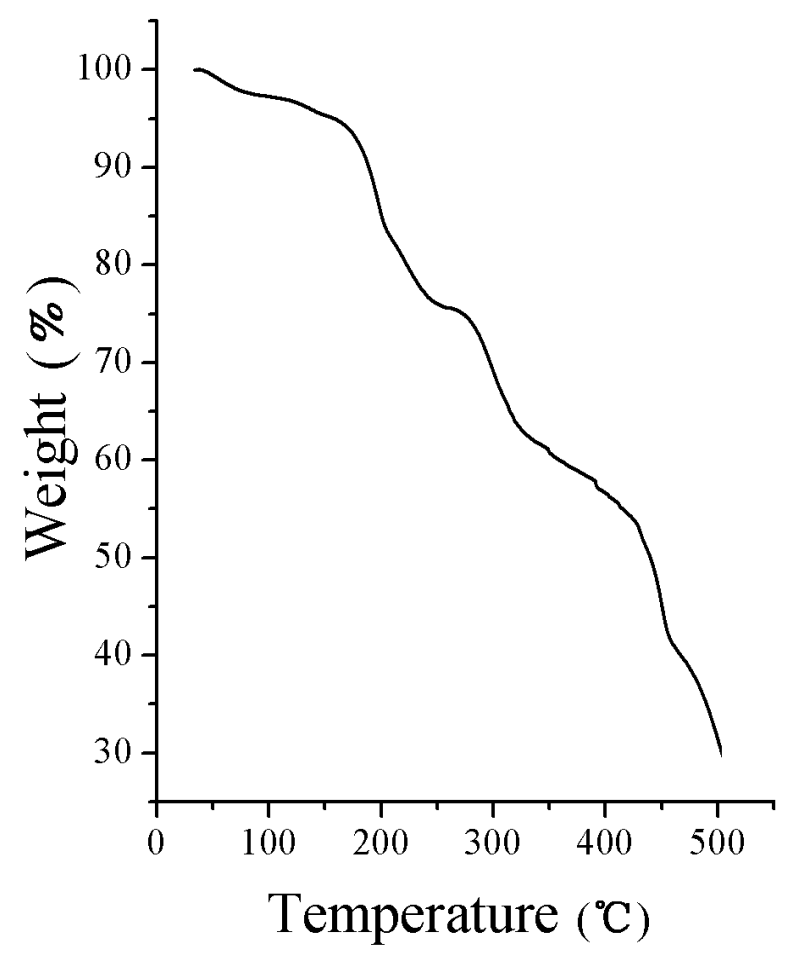

Figure S2. TGA curve for 1: the sample was heated from $30^{\circ} \mathrm{C}$ to $500^{\circ} \mathrm{C}$ at $10^{\circ} \mathrm{C} / \mathrm{min}$ under nitrogen atmosphere. 